\title{
An Impact of Technological Conditions on Surface Burning in Grinding of the Orbit
}

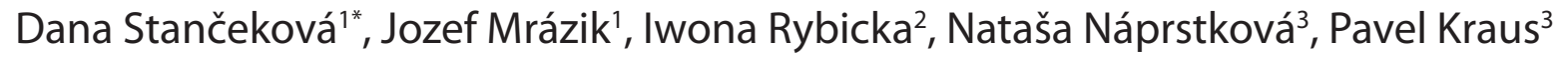 \\ 1 University of Žilina, Faculty of Mechanical Engineering, Univerzitna 1, 010 26, Žilina, Slovakia \\ 2 Lublin University of Technology, Faculty of Mechanical Engineering, ul. Nadbystrzycka Street 36, 20-618 Lublin, \\ Poland \\ ${ }^{3}$ J.E.Purkyně Univerzity, Faculty of Production Technology and Management, Ústí nad Labem, Czech Republic \\ * Correspomding author's e-mail: dana.stancekova@fstroj.uniza.sk
}

\begin{abstract}
A process of quality development helps us reveal concrete deficiences, an analysis of their origin and realization of required modifications that are needed to solve a concrete problem. One of the aims of quality development of production in bearing industries is to find out an impact of tchnological conditions to form burning of surfaces in grinding of orbits of bearing rings. We try to describe an origin of the problem, to find reasons of burned surfaces in a process of grinding and to propose such technological conditions to avoid above-stated problems and to produce the least possible number of non-identical workpieces. To lower a number of burnings in grinding of the orbit to zero percentage is not real, however, we have to try to get a minimal number of parts with damaged surface.
\end{abstract}

Keywords: grinding, orbit, quality, burning

\section{INTRODUCTION}

The modern period, termed even as a period of high competition, is typical of its high demands of customers on the quality of all products and services provided by suppliers. Quality has become a decisive factor of sales of products and services and one of the most efficient means how to successfully deal with fierce competitors and to secure development and prosperity of a company. The company management must form suitable environment and conditions to maintain quality.

A process of quality improvement helps us reveal concrete deficiencies, to analyze their reasons and to carry out required modifications necessary to solve a concrete issue. The aim of the below-stated experimental verification was to find out a level of an impact of technological conditions for formation of surface burning in grinding of the orbital path of outer rings of bearings. Our aim is to describe the origin of the issue, find reasons of surface burning in the process of grinding and to propose such technological conditions which would assist in avoiding of such problems and to produce the lowest amount of mismatching parts.

\section{THE STATE ANALYSIS IN GRINDING PROCESS}

The process of grinding of an orbital path of outer bearing rings runs, as an operation after turning, hardening, i.e, heat treatment of rings, grinding of faces and outside diameters [13,7]. After the process of grinding, the process of polishing follows and, finally, installing bearings into products that the company produces for car or other engineering industry $[12,10]$.

In the process of grinding, the ring obtains the accurate geometrical shape together with high quality surface. By the process, burnings of orbital path surface are formed and they are classified as a product mismatch. One of 
reasons may be a steel supplier, as steel can be of different quality $[13,1,14]$.

Burned spaces on the orbital path of rings are monitored by taking samples according to a scheduled test plan. In individual time intervals a person responsible takes samples of bearings on each shift for further analysis. Etching of bearings of selected samples takes place in the etching bath. By doing so, it is possible to reveal burnings by microscope, as they are not always visible with naked eye. The record is made and in case the burning takes place in selected samples, no further production is allowed. Maintenance is informed immediately and the machine by which the samples were produced is stopped until measures are taken to remove a burning from the orbital path surface $[13,15,3]$.

Expenses in production connected with surface burning of the orbital path of the bearing ring are quite considerable, as all the rings must be dropped away as mismatched parts and even the previous production made in a shift is controlled.

- a machine must be stopped until selected bearings are controlled, which causes delays in production,

- if surface burning of the orbital path reappears, technological conditions must be modified, e.g., applied abbrasive, revs of a workpiece and grinding spindle, feed speed..., another time delay, a production costs increase,

- if uncertainties related to surface burning persist, bearing rings are sent for analysis to a material laboratory in which the exact depth of burning is classified, another time delay, as the machine does not run,

- if an outcome is not required ring quality, feed speed lowers and further technological conditions are modified which results in an increase of time for production of one ring which equals a decrease in productivity and a production costs increase,

- the worst impact for the company is a customer complaint of a product due to surface burning of the orbital path of the bearing ring which may lead to a loss of customer trust and cancellations of further orders $[7,11]$.

\section{Grinding of orbital paths and holes of rings}

It is the most laborious finishing operation. Even up to $50 \%$ of mismatched parts come from this operation. Traditional hole grinding machines or CNC grinding machines are used, requirement of fixed and quality adjustment of the spindle is decisive. Regarding a small diameter of the grinding wheel, it is necessary to adjust relatively high speed to reach the cutting speed $[9,2]$.

Diameter of wheel is usually $(0.8 \div 0.9) \mathrm{D}$. $\mathrm{D}$ - diameter of the hole.

If the parameter drops below $0.6 \mathrm{D}$, it is necessary to change the wheel as it worsens edginess of the machined surface.

All more modern orbital and hole grinding machines machine after one ring, mostly in sliding rests to increase accuracy of an operation and a position of bearing surfaces. Positioning of sliding rests in the orbital grinding machine in fig. 1. The machine has the range of the ground hole $ø 18 \div 80 \mathrm{~mm}$. A maximum rotation of a working headstock is $20^{\circ}[9,4]$.

\section{THERMAL PHENOMENA IN MACHINING OF STEEL FOR ROLLER BEARINGS}

In the process of grinding there is caused a modification in the structure connected with a change of mechanical properties, an origin of the internal stress sometimes accompanied with cracks in the surface layer of a machined workpiece.

This is a way how adverse effects of thermal phenomena accompanying grinding manifest in several cases. According to structural modifications in the boundary layer of the machined surface one may assume that temperature reaches up to $1,000{ }^{\circ} \mathrm{C}$ and it is close to the melting point of steel. Even a stream of sparks originating also in an intesive cooling testifies about the high instantaneous temperature and also a shape of chips (melted into drops). A duration of the instantaneous temperature is very short, but on the other hand, there exist plenty of such intensive sources [6].

A stable temperature of the surface layer, which is lower againt the instantaneous one, depends on the mass of a workpiece, its thermal conductivity and intensity of cooling. According to conditions of grinding the stable temperature may reach up to $350{ }^{\circ} \mathrm{C}$ in the surface layer.

In the evaluation of thermal effects originating in grinding on a modification of the structure of ground material we may follow from phenomena existing in quenched steels in their tempering. As in tempering, heat led into a boundary surface layer causes a change of volume and hardness. Frequently, an oxygenation of the surface takes place in an increase of temperature in 


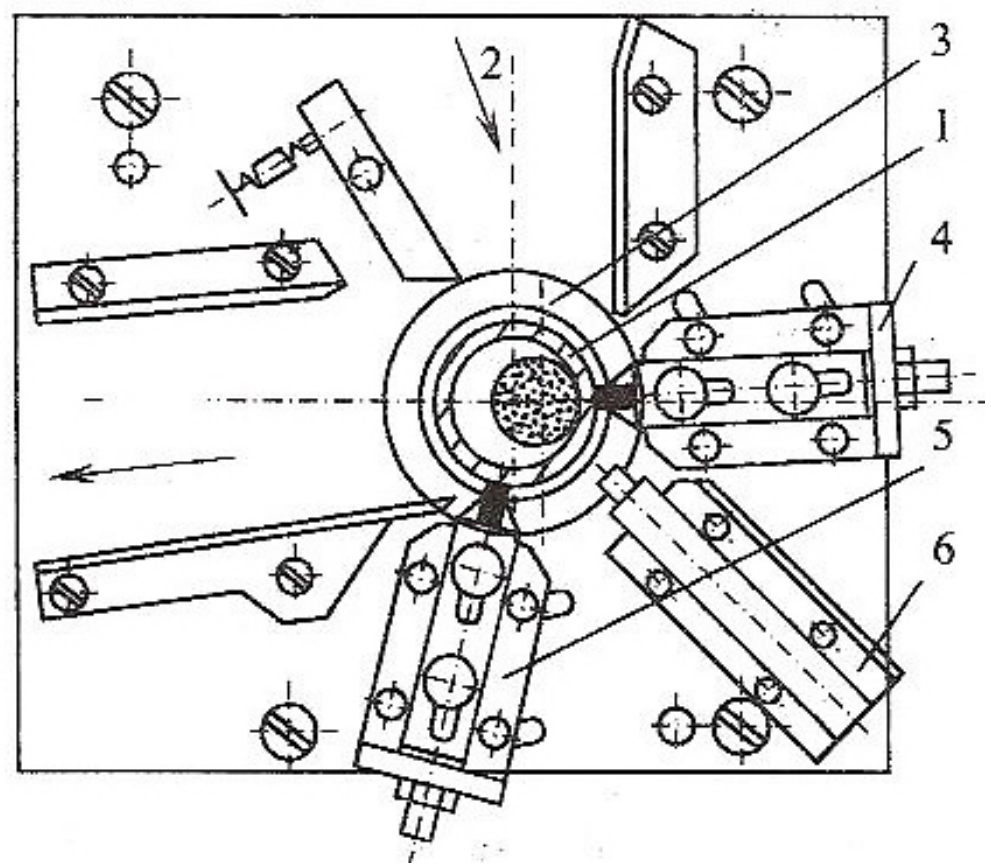

Fig. 1. Sliding rests in the orbital grinding machine

1 - ring, 2 - input, 3 - fixture, 4,5 - sliding rests, 6 - extractor [5].

the boundary level. If temperature reaches higher values in the boundary level, structural modifications appear in the affected layer.

Layer thickness with a modified structure and hardness is several hundreds up to tenths of mm. As such heated up spaces cause a decrease of bearing durability by means of a lowered contact fatigue strength of surface layers, there is a prescribed check for heat after grinding of workpieces $[5,8]$.

\section{TECHNOLOGICAL VERIFICATIONS}

Production of one of the most frequently manufactured and used bearing rings, the type AU 210-B-2S, runs in the sliding rests, we grind by means of the system BKS 2, cooling is with emulsion. The basic requirements are: to follow production period of 0.4 per a piece, drawing parameters and tolerances (radius of the orbital path $-\mathrm{R}=6.604 \mathrm{~mm}$, the shape of the path $0.004 \mathrm{~mm}$, circularity $0.003 \mathrm{~mm}$ ), to follow the required surface quality $\mathrm{Rz}=3 \mu \mathrm{m}$, surface burning, etc.

Verifications were focused on three important technological conditions - a machining allowance, cutting speed of a grinding wheel, a type of a grinding wheel. Further technological conditions are regarded to be met and correctly set up:

- a capability of the machine produces set up parameters within required tolerances and quality,
- a correct selection and control of input material,

- correct heat treatment,

- correct adjustment of the machine by a seter, sufficient cooling, correctly adjusted,

- a diamond rotary dresser meets set requirements,

- setting and speed of displacements will be modified minimally to keep a production period,

- system BKS 2 is active,

- a rotary speed within the range $300 \div 480 \mathrm{~min}^{-1}$ for roughing or honing.

\section{Technological testing - a modification of a size of an allowance}

A dependance of the size of a machining allowance on production period and quality of the orbital path surface of the bearing ring was measured on rings with a different machining allowance in set technological conditions, tab. 1. The system BKS 2 is active

In case of the small machining allowance $0.20 \div 0.25 \mathrm{~mm}$ we obtained very good production periods, a number of burned pieces was zero, however, on the orbital path, there appeared black non-ground spots which is inadmissible. Pieces were regarded as mismatched parts.

Moreover, in case of the allowance over $0.40 \mathrm{~mm}$ the production period starts to increase 
Table 1. A dependance of the size of a machining allowance on a prodution period and surface quality

\begin{tabular}{|c|c|c|c|}
\hline $\begin{array}{l}\text { The machining } \\
\text { allowance }[\mathrm{mm}]\end{array}$ & The production period per one piece [min] & $\begin{array}{l}\text { The number } \\
\text { of burned pieces }\end{array}$ & $R z[\mu \mathrm{m}]$ \\
\hline 0.20 & $0.356 ; 0.360 ; 0.352 ; 0.365 ; 0.361$ & 0 & $\begin{array}{l}3 \text { pieces with black spots on the } \\
\text { orbital path }\end{array}$ \\
\hline 0.25 & $0.372 ; 0.369 ; 0.370 ; 0.375 ; 0.377$ & 0 & $\begin{array}{l}1 \text { piece with black spots on the } \\
\text { orbital path }\end{array}$ \\
\hline 0.30 & $0.385 ; 0.388 ; 0.382 ; 0.389 ; 0.380$ & 0 & $2.1 ; 1.8 ; 2.0 ; 2.2 ; 2.3$ \\
\hline 0.35 & $0.392 ; 0.394 ; 0.390 ; 0.397 ; 0.391$ & 0 & $2.6 ; 2.5 ; 2.8 ; 2.4 ; 2.6$ \\
\hline 0.40 & $0.401 ; 0.398 ; 0.405 ; 0.400 ; 0.404$ & 0 & $2.8 ; 3.0 ; 2.9 ; 2.9 ; 2.7$ \\
\hline 0.45 & $0.413 ; 0.418 ; 0.410 ; 0.419 ; 0.415$ & 1 & $2.9 ; 3.1 ; 3.0 ; 2.9 ; 3.0$ \\
\hline 0.50 & $0.428 ; 0.435 ; 0.432 ; 0.440 ; 0.442$ & 2 & $3.3 ; 3.4 ; 3.6 ; 3.4 ; 3.5$ \\
\hline 0.55 & $0.448 ; 0.452 ; 0.450 ; 0.461 ; 0.465$ & 2 & $3.6 ; 3.7 ; 3.5 ; 3.8 ; 3.5$ \\
\hline 0.60 & $0.480 ; 0.477 ; 0.489 ; 0.492 ; 0.485$ & 4 & $3.8 ; 3.7 ; 3.7 ; 3.9 ; 3.8$ \\
\hline
\end{tabular}

and even burned workpieces appeared (fig. 2). Rz exceeded $3 \mu \mathrm{m}$. In case the allowance exceeded $0.60 \mathrm{~mm}$, the system BKS 2 aborted a cycle of grinding. These pieces can be ground up to the required quality only in slower displacements which would prolong the production period.

The best results were reached in case of the allowance $0.30 \div 0.35 \mathrm{~mm}$, when the production period was not exceeded, a number of burned piece was zero and $R z$ of the surface was safely below $3 \mu \mathrm{m}$. We must regard the fact that everything must be secured and followed so that all the

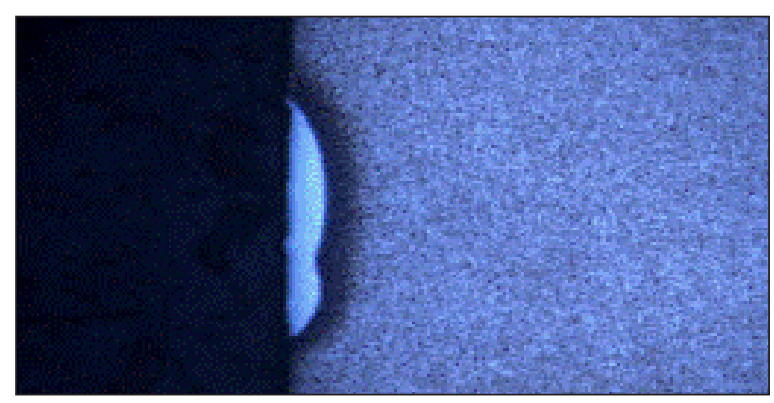

Fig. 2. A burning of the orbital path into the depth $0.035 \mathrm{~mm}$, the machining allowance is $0.55 \mathrm{~mm}$ allowances followed smooth operations and heat treatment (quenching and tempering).

\section{Technological testing - a modification of cutting speed and a type of grinding wheel 12A 90K 8V 716}

An impact of a cutting speed on surface quality in a given wheel type. Tests were performed on rings with the machining allowance $0.30 \div 0.35 \mathrm{~mm}$.

We found out at what cutting speed the surface quality will be maintained and whether there appear burned spaces on the orbital path of the outer bearing ring.

In Table 2 the quality of ground surface is evaluated - burned spots on the orbital path and $R z$ in the used cutting speeds of the wheel.

In the stated technological conditions and maintained production periods the cutting speed of the grinding wheel changed. In case of a lower cutting speed $28.3 \div 37.7 \mathrm{~m} . \mathrm{s}^{-1}$ burned spots did not take place on the orbital path, but $R z$ was above 3 $\mu \mathrm{m}$, which is insufficient. In case of higher cutting speed of the wheel $40.7 \div 50.1 \mathrm{~m} . \mathrm{s}^{-1}$ burned spaces took place on the orbital path (fig. $3,4,5$ ) although

Table 2. The impact of a cutting speed of the wheel 12 A 90 K 8 V 716 on surface quality

\begin{tabular}{|c|c|c|c|}
\hline $\begin{array}{c}\text { Rotations of the abbrasive } \\
\text { spindle }\left[\mathrm{min}^{-1}\right]\end{array}$ & $\begin{array}{c}\text { The cutting speed of the grinding } \\
\text { wheel } v_{w}\left[{\left.\mathrm{~m} . \mathrm{s}^{-1}\right]}^{-1}\right.\end{array}$ & $R z[\mu \mathrm{m}]$ & $\begin{array}{c}\text { A number of burned } \\
\text { pieces }\end{array}$ \\
\hline 9000 & 28.3 & $3.6 ; 3.8 ; 3.7 ; 3.5 ; 3.6$ & 0 \\
\hline 10000 & 31.3 & $3.3 ; 3.4 ; 3.4 ; 3.5 ; 3.3$ & 0 \\
\hline 11000 & 34.4 & $3.2 ; 3.3 ; 3.2 ; 3.4 ; 3.3$ & 0 \\
\hline 12000 & 37.7 & $3.1 ; 3.0 ; 3.2 ; 3.1 ; 3.2$ & 0 \\
\hline 13000 & 40.7 & $3.0 ; 2.9 ; 3.1 ; 3.0 ; 2.9$ & 1 \\
\hline 14000 & 43.9 & $2.9 ; 2.8 ; 3.0 ; 2.9 ; 3.0$ & 2 \\
\hline 15000 & 47.1 & $2.8 ; 2.7 ; 2.9 ; 2.7 ; 2.8$ & 3 \\
\hline 16000 & 50.1 & $2.7 ; 2.8 ; 2.6 ; 2.7 ; 2.8$ & 3 \\
\hline
\end{tabular}


surface roughness started to improve. This typed of grinding wheels is not sufficient for the stated production period and technological conditions.

\section{Technological testing - a modification of a cutting speed and a type of grinding wheel H 11 H K 100 K 4 X S}

According to the results of verification stated in Table 3, we may assume that as in the case of the previous wheel no burning spots took place by the speed $28.3 \div 31.3 \mathrm{~m} \cdot \mathrm{s}^{-1}$, roughness of surface was on the limit of tolerance. However, by the higher cutting speed $34.4 \div 50.1 \mathrm{~m} . \mathrm{s}^{-1}$ burning spots started to appear on the orbital path (fig. 6,7) although Rz improved.

\section{Technological testing - a modification of a cutting speed and a type of grinding wheel 27 A 150 H 4 V 716}

As far as quality concerned, better results were obtained for this wheel, tab. 4

During a verification process we found out that by the cutting speed $31.7 \div 37.7 \mathrm{~m} \cdot \mathrm{s}^{-1}$ no burned spots took place on the orbital path and Rz was below the level $3 \mu \mathrm{m}$, Fig. 8, 9. By the higher cutting speed $40.7 \div 50.1 \mathrm{~m} . \mathrm{s}^{-1}$, however, Rz

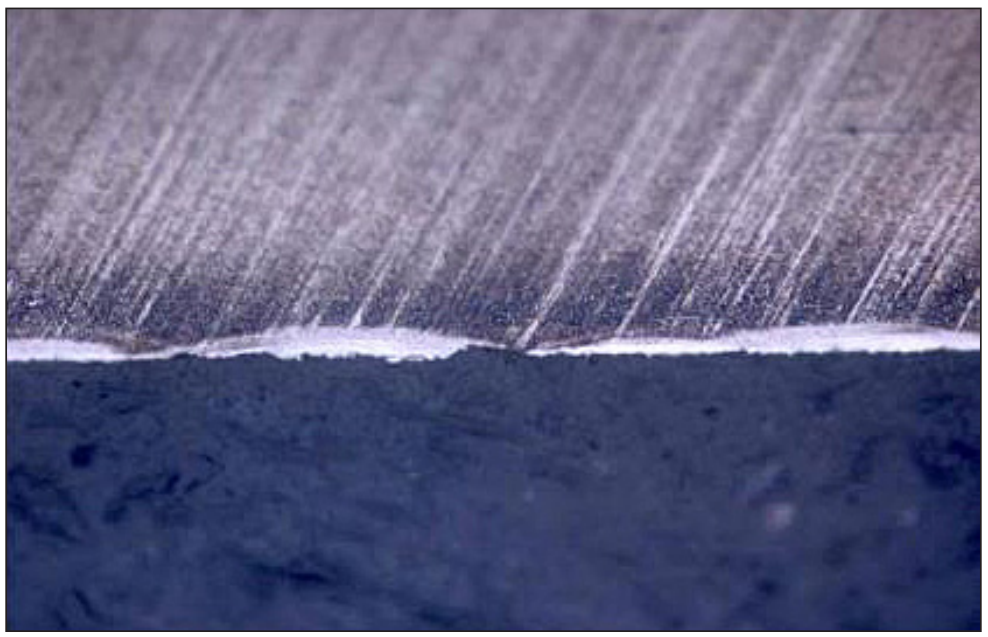

Fig. 3. The burning of the orbital path into the depth of $0,020 \mathrm{~mm}$ by the cutting speed vw $=47.1 \mathrm{~m} . \mathrm{s}-1$

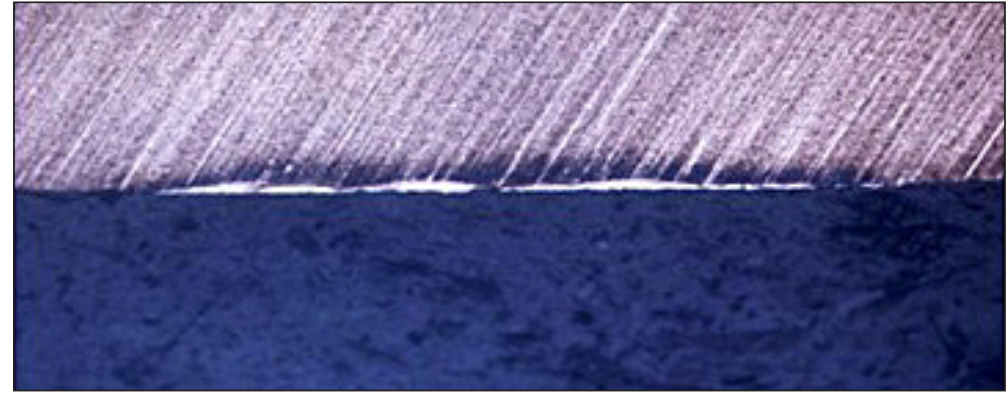

Fig. 4. The burning of the orbital path into the depth of $0.012 \mathrm{~mm}$ by the cutting speed $\mathrm{vw}=43.9 \mathrm{~m} . \mathrm{s}-1$

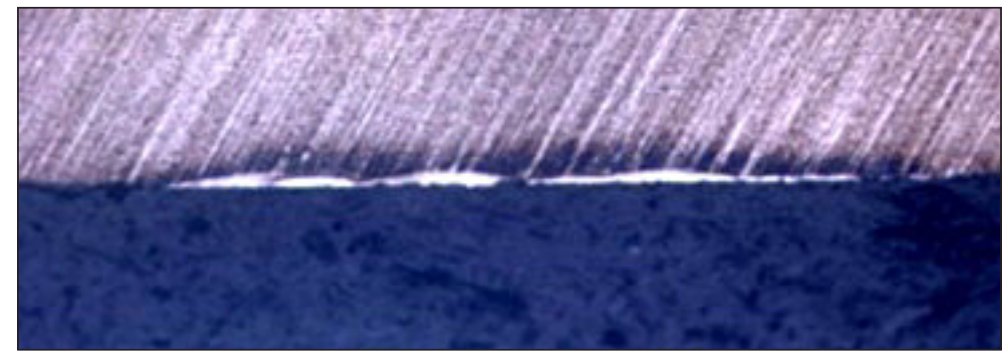

Fig. 5. The burning of the orbital path into the depth of $0.010 \mathrm{~mm}$ by the cutting speed $\mathrm{f} v \mathrm{vw}=40.7 \mathrm{~m} . \mathrm{s}-1$ 
Table 3. An impact of the cutting speed of the wheel H 11 H K $100 \mathrm{~K} 4 \mathrm{X}$ S on surface quality

\begin{tabular}{|c|c|c|c|}
\hline $\begin{array}{c}\text { Rotations of the abbrasive } \\
\text { spindle } \mathrm{n}\left[\mathrm{min}^{-1}\right]\end{array}$ & $\begin{array}{c}\text { The cutting speed of the grinding } \\
\text { wheel } \mathrm{v}_{\mathrm{w}}\left[{\left.\mathrm{m} . \mathrm{s}^{-1}\right]}^{-1}\right.\end{array}$ & $R z[\mu \mathrm{m}]$ & A number of burned pieces \\
\hline 9000 & 28.3 & $3.2 ; 3.3 ; 3.1 ; 3.3 ; 3.2$ & 0 \\
\hline 10000 & 31.3 & $3.1 ; 3.0 ; 2.9 ; 3.1 ; 3.0$ & 0 \\
\hline 11000 & 34.4 & $3.0 ; 2.9 ; 2.8 ; 2.9 ; 2.8$ & 1 \\
\hline 12000 & 37.7 & $2.9 ; 2.8 ; 2.8 ; 2.7 ; 2.9$ & 1 \\
\hline 13000 & 40.7 & $2.8 ; 2.7 ; 2.6 ; 2.7 ; 2.9$ & 2 \\
\hline 14000 & 43.9 & $2.7 ; 2.6 ; 2.7 ; 2.5 ; 2.8$ & 2 \\
\hline 15000 & 47.1 & $2.5 ; 2.6 ; 2.5 ; 2.4 ; 2.3$ & 3 \\
\hline 16000 & 50.1 & $2.4 ; 2.3 ; 2.2 ; 2.4 ; 2.3$ & 4 \\
\hline
\end{tabular}

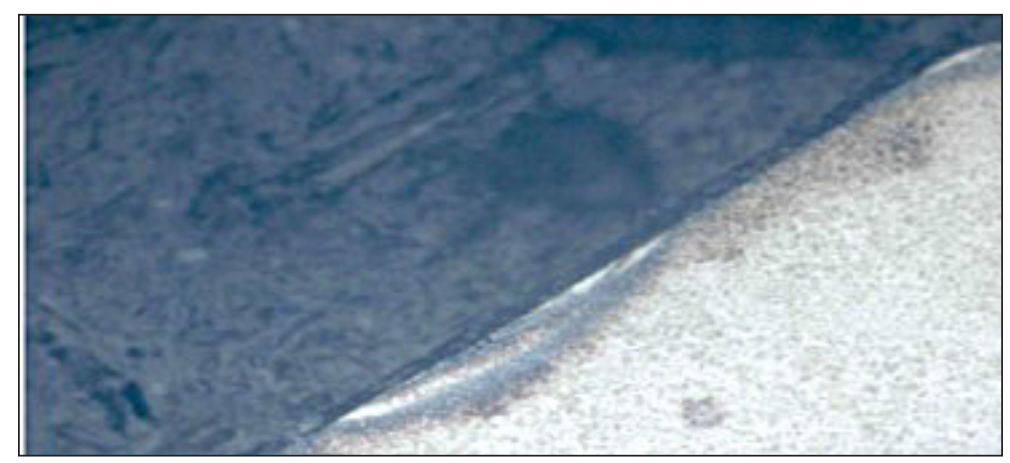

Fig. 6. The burning of the orbital path into the depth of $0.017 \mathrm{~mm}$ by the cutting speed $\mathrm{vw}=47.1 \mathrm{~m} . \mathrm{s}-1$

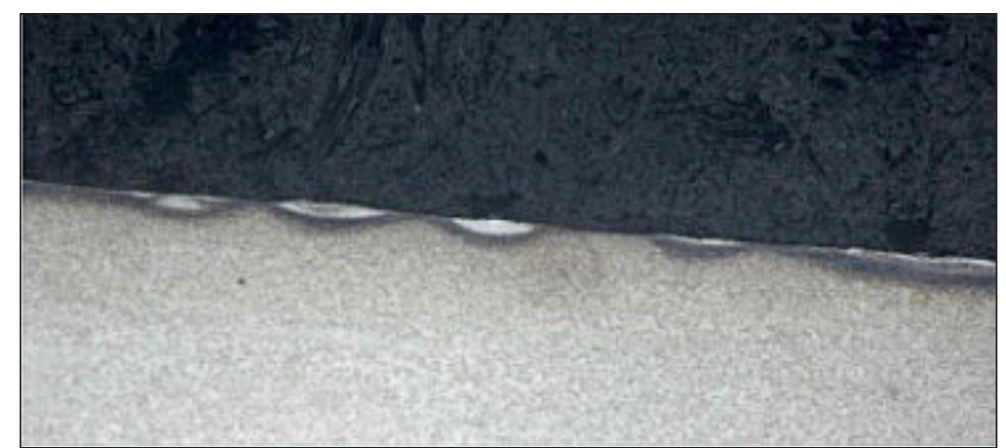

Fig. 7. The burning of the orbital path into the depth of $0.012 \mathrm{~mm}$ by the cutting speed $\mathrm{vw}=43.9 \mathrm{~m} . \mathrm{s}-1$

was very good but there took place birned spots on the path, Fig.10, 11. We obtained satisfactory results with this wheel by the cutting speed of $34.4 \mathrm{~m} . \mathrm{s}^{-1}$ and they are suitable for an aaplication in the production process.

\section{Evaluation of the technological testing}

The aim was to test three specified grinding wheels in set cutting conditions and various machining allowances for grinding the orbital path of the outer rings, while one of the basic conditions was to maintain a production period of $0.4 \mathrm{~min}$ per workpiece in specified quality of surface of the orbital path $-R z$ up to $3 \mu \mathrm{m}$ and no burned spots.

Technological paramaters, e.g., a speed of displacement, a period of spark out, a speed of dressing... could be modified only in a limited way so that the production period would be maintained. That is why the experimental verification was focused mainly on the cutting speed of the grinding wheels and a size of an allowance for machining.

According to technological tests, the best results were obtained by the wheels $27 \mathrm{~A} 150 \mathrm{H} 4 \mathrm{~V} 716$ by the constant cutting speed 
Table 4. An impact of the cutting speed of the grinding wheel 27 A 150 H 4 V 716 on the surface quality

\begin{tabular}{|c|c|c|c|}
\hline $\begin{array}{c}\text { Rotations of the abbrasive } \\
\text { spindle } \mathrm{n}\left[\mathrm{min}^{-1}\right]\end{array}$ & $\begin{array}{c}\text { The cutting speed of the grinding } \\
\text { wheel } \mathrm{v}_{\mathrm{w}}\left[\mathrm{m.s}^{-1}\right]\end{array}$ & $R z[\mu \mathrm{m}]$ & A number of burned pieces \\
\hline 9000 & 28.3 & $3.0 ; 2.9 ; 2.8 ; 2.9 ; 3.1$ & 0 \\
\hline 10000 & 31.3 & $2.8 ; 2.7 ; 2.9 ; 2.7 ; 3.0$ & 0 \\
\hline 11000 & 34.4 & $2.7 ; 2.6 ; 2.8 ; 2.7 ; 2.6$ & 0 \\
\hline 12000 & 37.7 & $2.6 ; 2.5 ; 2.7 ; 2.6 ; 2.5$ & 0 \\
\hline 13000 & 40.7 & $2.6 ; 2.4 ; 2.5 ; 2.4 ; 2.3$ & 1 \\
\hline 14000 & 43.9 & $2.4 ; 2.3 ; 2.2 ; 2.3 ; 2.4$ & 1 \\
\hline 15000 & 47.1 & $2.2 ; 2.3 ; 2.2 ; 2.1 ; 2.0$ & 2 \\
\hline 16000 & 50.1 & $2.0 ; 1.9 ; 2.1 ; 1.8 ; 1.9$ & 3 \\
\hline
\end{tabular}

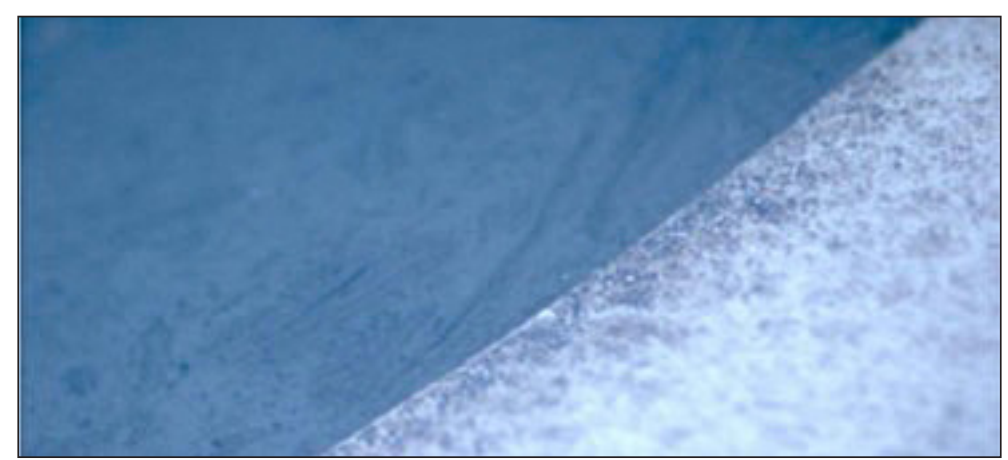

Fig. 8. The orbital path without a burned spot by the cutting speed vw $=31.3 \mathrm{~m} . \mathrm{s}-1$

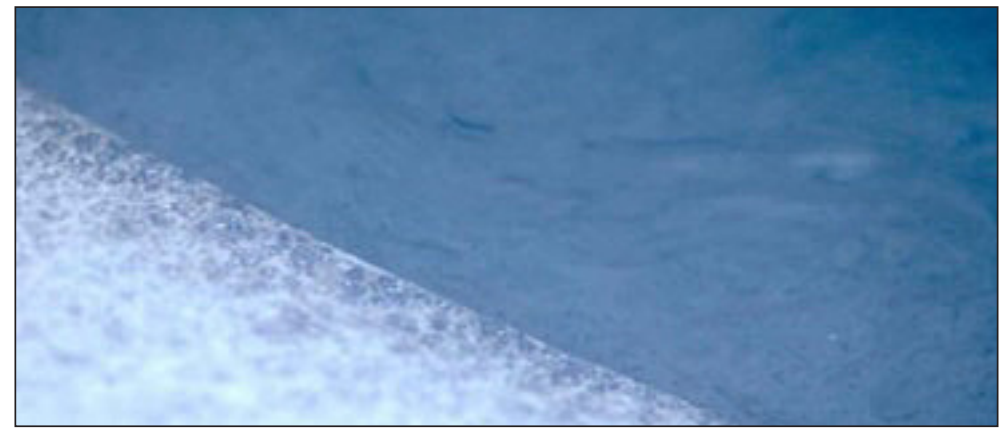

Fig. 9. The orbital path without a burned spot by the cutting speed vw $=34.4 \mathrm{~m} . \mathrm{s}-1$

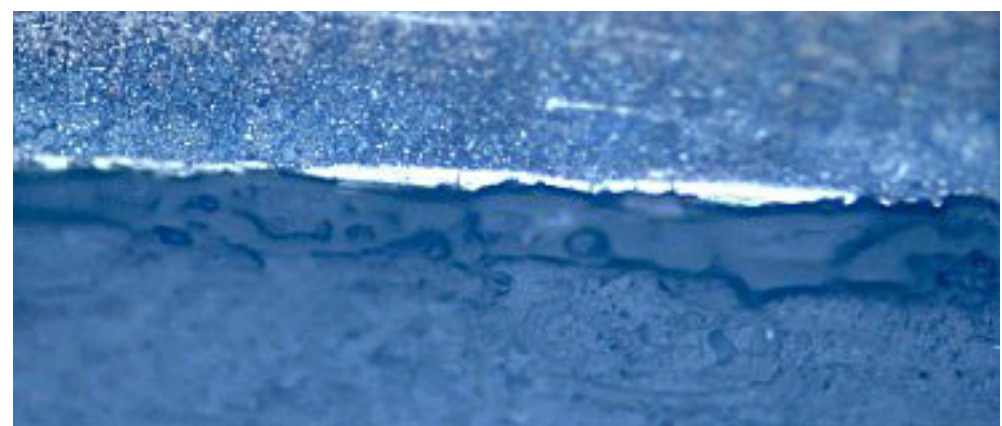

Fig. 10. The orbital path without a burned spot by the cutting speed vw $=34.4 \mathrm{~m} . \mathrm{s}-1$ 


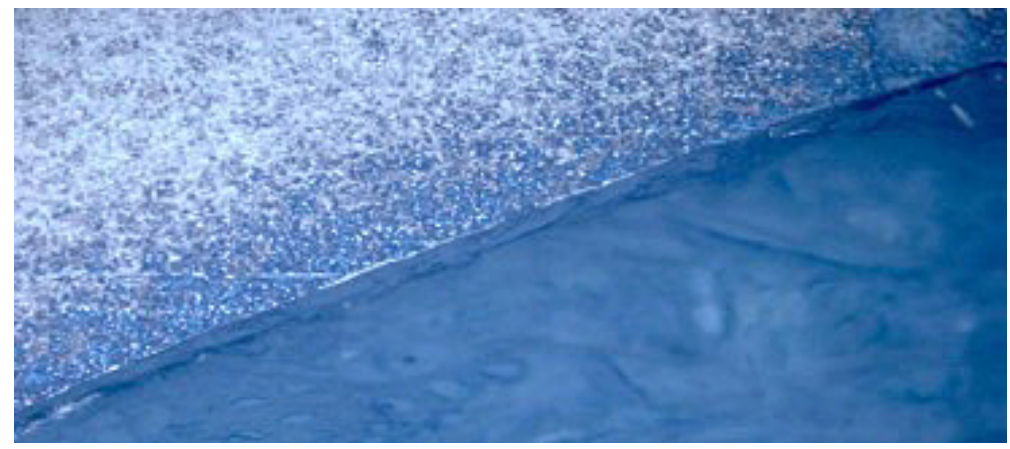

Fig. 11. Burned spots of the orbital path into the depth of $0.002 \mathrm{~mm}$ by the cutting speed vw $=40.7 \mathrm{~m} . \mathrm{s}-1$

$v_{w}=34.4 \mathrm{~m} \cdot \mathrm{s}^{-1}$. The size of machining allowance varied from $0.30 \mathrm{~mm}$ to $0.35 \mathrm{~mm}$. Under these conditions also surface quality was maintained and burned spots did not take place on the orbital path. In case that the allowance was smaller than $0.30 \mathrm{~mm}$, black non-ground spots started to appear. In case of allowance bigger than $0.40 \mathrm{~mm}$, surface quality worsened and a number of burned workpieces started to increase. A production period also increased. If we intend to decrease a number of burned pieces, we must maintain other conditions: quality material, heat treatment, sufficient cooling, a deterioration of a rotary dresser, a human factor

\section{CONCLUSIONS}

The aim of the performed experimental verifications was to find an impact of technological conditions on the formation of burned spots in grinding the orbital path of outer surface of bearing rings. Suitable grinding wheels were selected for stated technological conditions so that we would avoid a formation of burned spots and we would maintain parameters, quality and a production period. To avoid burned spots in grinding, it is necessary to follow also other conditions connected with material quality, ring machining in soft operations, heat treatment, a human factor, etc. Regarding the above-mentioned facts, our aim was to lower a number of burned spots in the production process from a monthly production below $1 \%$ in a given segment. Despite that fact it is probably unreal to remove burned spots to the level $0 \%$, we must try to lower the share of burned space to minimum, as they represent striking losses for the company from economical and technocal standpoints.

\section{Acknowledgement}

The article was made under support grant project KEGA 022ŽU-4/2017 Implementation of on-line education in the area of precise technologies with an impact on educational process to increase skills and flexibility of students of engineering fields of study.

\section{REFERENCES}

1. Cep R., Janasek A., Petru J., Sadilek M., Mohyla P., Valicek J., Harnicarova M. and Czan A. Surface Roughness after Machining and Influence of Feed Rate on Process. Key Engineering Materials, vol. 581, 341-347.

2. Dodok T., Čuboňová N. and Kuric I. Workshop Programming as a Part of Technological Preparation of Production In: Advances in science and technology, volume 11, Issue: 1, 111-116

3. Hrubý J., Schindlerová V. ad Rentka J. Degradation Processes in the Contact Layers of Forming Tools. Manufacturing Technology, vol. 15/5, 2015, 836-842.

4. Konar R., Mician M. and Hlavaty I. Defect detection in pipelines during operation using magnetic flux leakage and phased array ultrasonic method. Manufacturing Technology, volume 14/3, 2014, 337-341.

5. Matejka B. and Máca J.: Technológia valivých ložísk - Obrábanie. Žilina, VŠDS, 1984

6. Náprstková N., Cais J., Kraus P. and Van T.N. Tool wear evaluation of selected inserts after turning by electron microscopy. Manufacturing Technology, volume 16, Issue 5, 2016, 1068-1073.

7. Neslušan M., Mičietová A. and Čilliková M. Monitoring of surface burn after grinding larger bearing rings. AIP Conference Proceedings, Vol. 1581 33, 2014, 1264-1271.

8. Petru J., Schiffner J., Zlamal T, Sadílek, M. and 
Stancekova D. Investigations of cutting tool wear while machining inconel 718. Manufacturing Technology, vol. 15/3, 2015, 396 - 403.

9. Pilc J. and Stančeková D.: Základy stavby obrábacích strojov. EDIS, 2004

10. Rudawska, A.: Selected aspects of the effect of mechanical treatment on surface roughness and adhesive joint strength of steel sheets. In. International journal of adhesion and adhesives, Vol. 50, 2014, 235-243.

11. Schindlerová V. and Šajdlerová I. Research wear forming tools in the technological flow. ITEP 2016: Innovative Technologies in Engineering Production. Zuberec, Slovak republic 2016, 125-126.

12. Stančeková D., Drbúl M., Janota M., Náprstková N., Kulla A. and Mrázik J. Influence of manufacturing parameters on final quality of lapped parts. Manufacturing technology : journal for science, research and production, vol. 16/1, 2016, 253-259.

13. Stančeková D., Štekláč D., Petru J., Zlámal T., Sadílek M., Janota, M. and Kordík M. Influence of Machining and Heat Treatment on Deformations of Thin-Walled Bearings. Materials Science Forum, vol. 862, 2016, 49-58.

14. Stuchlý V., Poprocký R. and Kaczmarek M. Reliability evaluation as a means of increasing the efficiency of equipment maintenance. Advances in science and technology, vol. 10, no. 32, 2016, 40 - 46.

15. Vasilko K. ana Pilc J. Results if machining by tool of self-propelled rotation due to wear. Manufacturing Technology, Volume 17, Issue 1, 2017, 100-103. 